\title{
FALL METABOLISM IN RELATION TO AMBIENT TEMPERATURES IN THREE SPECIES OF MYOTIS
}

\author{
MICHAEL J. O'FARRELL and EUGENE H. STUDIER \\ Department of Biology, New Mexico Highlands University, Las Vegas, New Mexico
}

(Received 19 Yanuary 1970)

\begin{abstract}
A zone of thermoneutrality exists for aduit female Myotis thysanodes in early September in an ambient temperature range of $32.5-34.5^{\circ} \mathrm{C}$ with minimum metabolism of $1.74 \mathrm{~cm}^{3} / \mathrm{g}$ per hr.

2. A transition from a homeothermic to a non-homeothermic metabolism to ambient temperature relation is evident by late September in adult female $M$. thysanodes.

3. In early September, some adult female $M$. yumanensis exhibit a homeothermic metabolism to ambient temperature relation while others exhibit a non-homeothermic relation.

4. In early September, adult $M$. lucifugus occultus of both sexes exhibit a non-homeothermic relation.

5. At ambient temperatures above $32.5^{\circ} \mathrm{C}$, metabolism in $M$. thysanodes increases at a significantly more rapid rate than in $M$. lucifugus occultus.

6. A critical thermal maximum ambient temperature of $44.5^{\circ} \mathrm{C}$ has been found for each of these three species.
\end{abstract}

\section{INTRODUCTION}

OXYGEN consumption and temperature regulation for many species of Myotis have been studied extensively (Hock, 1951; Reite \& Davis, 1961; Henshaw \& Folk, 1966; Stones \& Wiebers, 1965, 1967). Recently, Licht \& Leitner (1967) reported metabolic activity for Myotis yumanensis in high ambient temperatures. Stones \& Wiebers (1967) reported seasonal oxygen consumption in $M$. lucifugus. Although $M$. lucifugus has been dealt with frequently, only the eastern subspecies has been used. The present study is concerned with M. lucifugus occultus (Findley $\&$ Jones, 1967), $M$. yumanensis and $M$. thysanodes. These species roost sympatrically in maternity colonies from late spring to early fall in the attic of Montezuma Seminary, Montezuma, San Miguel Co., New Mexico (Studier, 1968). Variations in metabolism-ambient temperature relationships may indicate physiological species differences coinciding with morphological differences within the three species.

\section{MATERIALS AND METHODS}

Adult bats of both sexes were routinely collected at about $08.00 \mathrm{hr}$ from the attic of Montezuma Seminary on various dates from 9 to 25 September 1969. Bats were immediately brought to the laboratory where four were weighed and placed in the exposure chambers under dim light conditions. Air was conducted through a drying column before 
entering the apparatus, and metabolism was determined using the technique of Studier et al. (1967). Myotis thysanodes were studied at intervals of $4^{\circ} \mathrm{C}$ throughout the ranges of 26.5$46.5^{\circ} \mathrm{C}, 28 \cdot 5-44 \cdot 5^{\circ} \mathrm{C}, 24 \cdot 5-4 \cdot 5^{\circ} \mathrm{C}$ and $22 \cdot 5-6.5^{\circ} \mathrm{C}$. Four animals were studied in each ambient temperature $\left(T_{a}\right)$ range resulting in a total of sixteen animals studied at $2^{\circ} \mathrm{C}$ intervals from 4.5 to $46.5^{\circ} \mathrm{C}$. Ambient temperature in the exposure chambers was maintained within $0.3^{\circ} \mathrm{C}$ of the desired level. Eight $M$. lucifugus occultus and four $M$. yumanensis were tested in $T_{a}$ 's from 16.5 to $44.5^{\circ} \mathrm{C}$. A final group of four $M$. thysanodes was tested in late September in $T_{a}$ 's from 32.5 to $4.5^{\circ} \mathrm{C}$. Bats were found to come to constant metabolic rate about $2 \mathrm{hr}$ after their introduction into the metabolic chambers. Data were collected at 10-min intervals until readings stabilized for three successive readings. $T_{a}$ was then changed by $4^{\circ} \mathrm{C}$ and readings begun again. Upon conclusion of each experiment, bats were reweighed and mean body weight determined and used to calculate oxygen consumption. All data were corrected to dry air at standard temperature and pressure. Regression lines were calculated using mean oxygen consumption of all bats tested at any given $T_{a}$ except where indicated otherwise.

\section{RESULTS}

The relationship of oxygen consumption (OC) to $T_{a}$ in $M$. thysanodes in early September (Fig. 1) is a homeothermic response. A zone of thermoneutrality exists in a $T_{a}$ range from 32.5 to $34.5^{\circ} \mathrm{C}$ with mean experimental $\mathrm{OC}$ of $1.74 \mathrm{~cm}^{3} / \mathrm{g}$ per hr

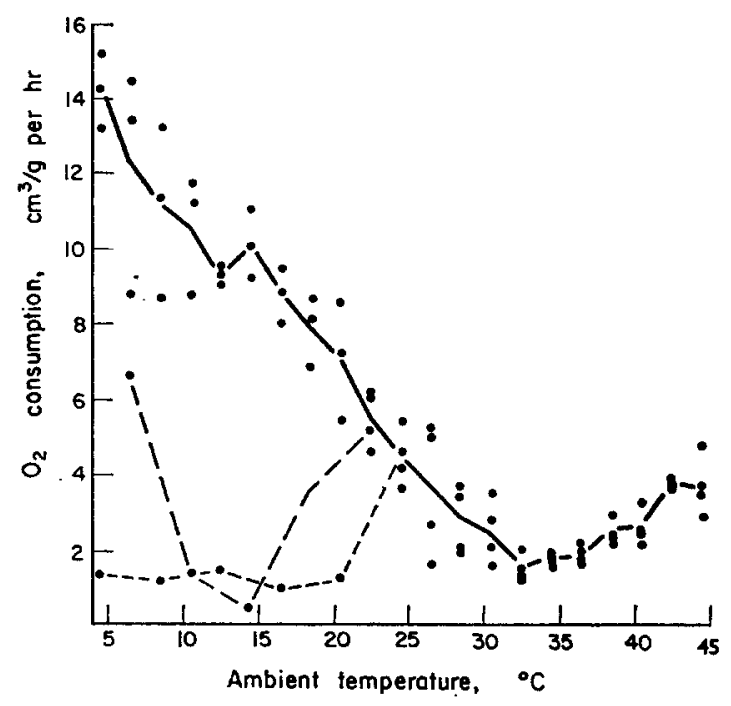

FIG. 1. The relationship of OC- $T_{a}$ in adult female $M$. thysanodes taken in early September. Each dot represents an individual reading. The solid line connects the means excluding several aberrant readings; these aberrant readings are separated by individual bats and connected by the dotted lines.

(S.E. $\bar{x}=0.092 ; n=8$ ). A regression line, calculated by the method of least squares, for $T_{a}$-metabolism data of $M$. thysanodes below and above the zone of thermoneutrality, results in the respecrive equations:

$$
\mathrm{OC}=15 \cdot 5-0.429 T_{a}
$$


and

$$
\mathrm{OC}=0.239 T_{a}-6 \cdot 61 \text {. }
$$

Solving these equations simultaneously, one finds a calculated minimal metabolic rate of $1.30 \mathrm{~cm}^{3} / \mathrm{g}$ per $\mathrm{hr}$ at a thermoneutral point of $33 \cdot 1^{\circ} \mathrm{C}$. Maximum measured metabolism in the $M$. thysanodes ranged from 13.3 to $15 \cdot 2 \mathrm{~cm}^{3} / \mathrm{g}$ per hr at $4 \cdot 5^{\circ} \mathrm{C}$. Critical ambient temperature and upper critical temperature (Stones $\&$ Wiebers, 1967 ) are 30.5 and $38.5^{\circ} \mathrm{C}$, respectively.

Responses of $M$. thysanodes to high temperatures were uniform. At $40.5^{\circ} \mathrm{C}$ these bats started showing signs of wetness on the fur and when $T_{a}$ reached $44.5^{\circ} \mathrm{C}$ all bats showed signs of distress. The fur was wet and matted, although lapping of the fur was not observed, and water was observed in the tubes leading out of the exposure chambers. $M$. thysanodes died within a $\frac{1}{2} \mathrm{hr}$ at $44 \cdot 5^{\circ} \mathrm{C}$. Postmortem examination revealed that the prime areas of wetness were the middle of the back and the abdomen, with some moisture about the shoulders.

Although most $M$. thysanodes exhibited homeothermic-like metabolism, two individuals tested at low $T_{a}$ 's in early September were not included in the calculations inasmuch as they exhibited a non-homeothermic-like metabolism. This physiological transition is nearly complete for $M$. thysanodes by late September (Fig. 2). At that time, $M$. thysanodes did not exhibit a thermoneutral zone. They do, however, exhibit increased $\mathrm{OC}$ at $T_{a}$ 's below $10^{\circ} \mathrm{C}$, reaching a mean peak metabolism of $6.87 \mathrm{~cm}^{3} / \mathrm{g}$ per hr at $4.5^{\circ} \mathrm{C}$.

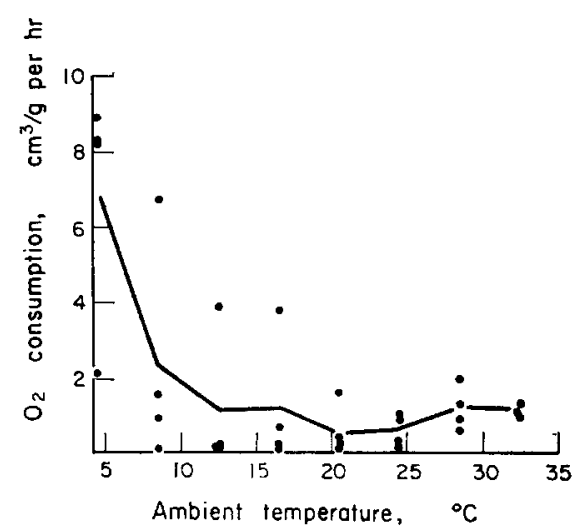

FIg. 2. The relationship of $\mathrm{OC}-T_{a}$ in adult female $M$. thysanodes taken in late September. The symbols used are the same as in Fig. 1.

The relation of $\mathrm{OC}$ and $T_{a}$ in $M$. lucifugus occultus in mid-September is shown in Fig. 3. Like the late-September $M$. thysanodes, this species exhibits a nonhomeothermic-like metabolism- $T_{a}$ response. A few individuals showed unusually high $\mathrm{OC}$ at $16.5^{\circ} \mathrm{C}$, which may be valid measurements or a case of non-equilibrium at the initial tested $T_{a}$. 
The response to high $T_{a}$ in $M$. lucifugus occultus was similar to that observed for $M$. thysanodes. All $M$. lucifugus occultus died within a $\frac{1}{2} \mathrm{hr}$ at $T_{a}$ of $44 \cdot 5^{\circ} \mathrm{C}$. One bat had a wet back, while the others had a wet muzzle and throat, with a damp to wet abdomen. No water was observed in the tubes leading from the chambers.

The relationship of OC to $T_{a}$ in $M$. yumanensis in mid-September is shown in

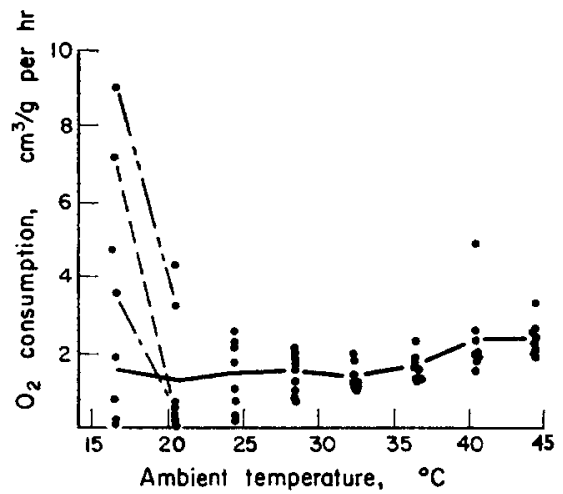

Fig. 3. The relationship of $\mathrm{OC}-T_{a}$ in adult $M$. lucifugus occultus taken in early September. Two females and six males were used. The symbols used are the same as in Fig. 1.

Fig. 4. This species demonstrated a highly variable metabolic state during this time of year. One animal showed a thermoneutral zone of $32.5-36.5^{\circ} \mathrm{C}$ and the remainder of the bats were at various stages of losing their homeothermic-like response.

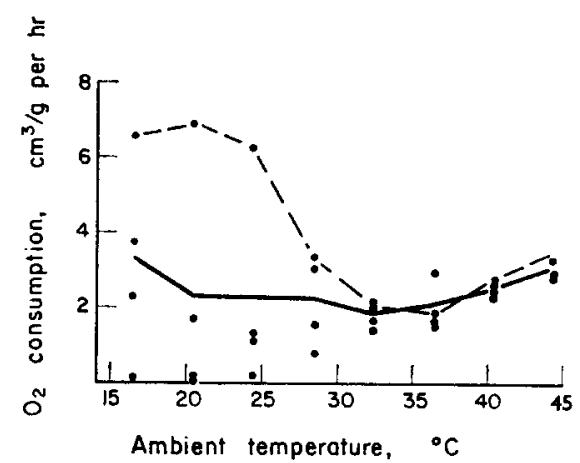

Fig. 4. The relationship of $\mathrm{OC}-T_{a}$ in adult female $M$. yumanensis taken in early September. The symbols used are the same as in Fig. 1; the dotted line indicates an individual that exhibited a homeothermic-like response.

High $T_{a}$ response for $M$. yumanensis is grossly similar to that of the other two species tested. Myotis yumanensis died within 40 min exposure to a $T_{a}$ of $44 \cdot 5^{\circ} \mathrm{C}$. These bats were wet over the muzzle and entire ventral surface, but only damp on the back. 


\section{DISCUSSION}

$M$. lucifugus and $M$. yumanensis in the attic decreased in number rapidly around the first week in September; however, $M$. thysanodes is very abundant until the end of September. Temperatures fluctuated greatly within the attic during September. A recording hygrothermograph, suspended in the attic next to a large group of $M$. thysanodes from 9 to 15 September, showed $T_{a}$ ranges from 12.2 to $41 \cdot 1^{\circ} \mathrm{C}$; mean maximum $T_{a}=36.9^{\circ} \mathrm{C}$ and mean minimum $T_{a}=13.5^{\circ} \mathrm{C}$. Relative humidity did not exceed $16 \%$ with large fluctuations occurring daily.

During the first part of September $M$. lucifugus and $M$. yumanensis were in deep torpor in the morning. When these bats were picked up they were not capable of much movement for approximately $15 \mathrm{~min}$. On the contrary, $M$. thysanodes at this time appeared torpid, but if touched were capable of flight immediately. By the end of September, $M$. thysanodes were very torpid in the morning. It would take around $15 \mathrm{~min}$ for these bats to attain flight. In the afternoon, however, all bats were very active.

In early September, fourteen out of sixteen $M$. thysanodes exhibited a thermoneutral zone and a $T_{a}$-OC pattern identical to winter-spring $M$. lucifugus (Stones \& Wiebers, 1967). It is unusual that in early September, post-lactating $M$. thysanodes should exhibit a $T_{a}-\mathrm{OC}$ pattern similar to early-pregnant $M$. lucifugus instead of one similar to their post-lactation pattern which is decidedly different. Also, in early September, two of sixteen $M$. thysanodes did not exhibit a homeothermic-like $T_{a}-\mathrm{OC}$ pattern. It would appear that a transition was occurring from a homeothermic-like to a non-homeothermic-like state, presumably a physiological reorientation preparatory for hibernation. By the end of September this physiological switch was almost complete. All bats entered torpor as $T_{a}$ was lowered, but below $10^{\circ} \mathrm{C}$ the metabolic rate started to increase. Reite \& Davis (1961) reported increased $\mathrm{OC}$ at $T_{a}$ 's below $5^{\circ} \mathrm{C}$ in $M$. lucifugus and Lasiurus borealis. By 6 October, the transition to non-homeothermic-like metabolism appeared complete, for ten individuals of this species were placed in a refrigerator $\left(T_{a}=4^{\circ} \mathrm{C}\right)$ and hibernation was achieved at this time.

$M$. lucifugus occultus, when first tested on 15 September, had completed a transition from a homeothermic-like to a non-homeothermic-like state. This agrees with Stones \& Wiebers (1967) in that their late summer bats (after 29 July) had lost the ability to resist torpor.

$M$. yumanensis appears to be in an intermediate category. At a time when $M$. thysanodes is starting to show a small change towards this transition, $M$. yumanensis appears to be much farther along in the transition. In an admittedly small sample, one individual seemed to exhibit a homeothermic-like response while the other three bats seemed to exhibit a nearly non-homeothermic-like response.

A critical thermal maximum $T_{a}\left(T_{a}\right.$ at which short-term exposure proved lethal) of $44.5^{\circ} \mathrm{C}$ has been found for these three species. Licht \& Leitner (1967) stated that one $M$. yumanensis survived for $60 \mathrm{~min}$ at a $T_{a}$ of $44.5-45^{\circ} \mathrm{C}$ while two others remained unusually still and panted throughout the test. Stones \& Wiebers 
(1967) stated that $M$. lucifugus effectively lowered their body temperature at a $T_{a}$ of $43.4^{\circ} \mathrm{C}$ by panting and salivating. Hock (1951) stated that $M$. lucifugus died quickly at a $T_{a}$ of $44^{\circ} \mathrm{C}$ in the exposure chamber. Myotis lucifugus are known to exist in extremely hot nursery colonies at $T_{a}$ 's up to $54^{\circ} \mathrm{C}$ (Henshaw \& Folk, 1966) and $55^{\circ} \mathrm{C}$ (Davis $e t a l ., 1965$ ). The three species of bats in the present study might not have been able to thermoregulate efficiently in the small exposure chambers, which might account for the discrepancy between the critical thermal maximum and actual roost temperatures. These bats, also, may not have been physiologically capable of coping with $T_{a}$ of this intensity at this time of year.

Panting and wetting of the fur with saliva were observed in all three species and agrees well with observations on $M$. lucifugus (Stones \& Wiebers, 1967).

Table 1 gives regression coefficients showing the relationship of $\mathrm{OC}-T_{a}$ at $T_{a}$ 's above the thermoneutral point for the three species tested. Although differences between the species existed, especially between the small-eared $M$. yumanensis and $M$. lucifugus and the large-eared $M$. thysanodes, the regression coefficients are not significantly different.

TABLE 1-REgRESSION COEFFICIENTS SHOWING THE RELATIONSHIP OF OXYGEN CONSUMPTION TO AMBIENT TEMPERATURE AT AMBIENT TEMPERATURES ABOVE THE THERMAL NEUTRAL POINT FOR THREE SPECIES OF Myotis

\begin{tabular}{lc}
\hline \multicolumn{1}{c}{ Species } & Regression coefficient \\
\hline M.thysanodes & 0.239 \\
M. yumanensis & 0.107 \\
M. lucifugus & 0.0872 \\
\hline
\end{tabular}

An analysis of variance (Edwards, 1950) was carried out on OC of each species at $4^{\circ} \mathrm{C}$ intervals from 32.5 to $44.5^{\circ} \mathrm{C}$. Results show that $T_{a}$ has a significant directly proportional affect on metabolic rate $(F=26.3$ for 3 and 39 d.f., $P<0.001)$ and, also, that the inter-species metabolic response differences approached significance ( $F=3.33$ for 2 and 13 d.f.). Since analysis of variance on $\mathrm{OC}$ of each species at $44.5^{\circ} \mathrm{C}$ showed significant species differences $(F=13.6$ for 2 and 13 d.f., $P<0.01)$ and, further, analysis of variance on metabolic differentials of each species $\left(\mathrm{OC}\right.$ at $44.5^{\circ} \mathrm{C}$ minus $\mathrm{OC}$ at $32.5^{\circ} \mathrm{C}$ ) showed significant species differences $(F=$ 7.34 for 2 and 13 d.f., $P<0.01$ ), we can conclude that $T_{a}$ 's above the thermal neutral point cause a significantly more rapid rise in $\mathrm{OC}$ in $M$. thysanodes than in $M$. lucifugus occultus.

The existence of the physiological and ecological differences between these three sympatric species must act as a species-isolating mechanism.

Acknowledgements-This study was financed in part by the Institute of Scientific Research, New Mexico Highlands University. We thank Professors James S. Findley, Philip Leitner and Robert C. Stones for their critical evaluations of the manuscript. We also thank William G. Ewing for assistance in the laboratory. 


\section{REFERENCES}

Davis W. H., Hassell M. D. \& Harvey M. J. (1965) Maternity colonies of the bat Myotis $l$. lucifugus in Kentucky. Am. Midl. Nat. 73, 161-165.

Edwards A. L. (1950) Experimental Design in Psychological Research. Holt, Rinehart \& Winston, New York.

Findley J. S. \& Jones C. (1967) Taxonomic relationships of bats of the species Myotis fortidens, $M$. lucifugus, and $M$. occultus. F. Mammal. 48, 429-444.

Henshaw R. E. \& Folk G. E. (1966) Relation of thermoregulation to seasonally changing microclimate in two species of bats (Myotis lucifugus and M. sodalis). Physiol. Zoöl. 39, 223-236.

Hock R. J. (1951) The metabolic rates and body temperatures of bats. Biol. Bull. 101, 289-299.

Licht P. \& Leitner P. (1967) Physiological responses to high environmental temperatures in three species of microchiropteran bats. Comp. Biochem. Physiol. 22, 371-387.

Reite O. B. \& Davis W. H. (1961) Thermoregulation in bats exposed to low ambient temperatures. Proc. Soc. exp. Biol. Med. 121, 1212-1215.

Stones R. C. \& Wiebers J. E. (1965) A review of temperature regulation in bats (Chiroptera). Am. Midl. Nat. 74, 155-167.

Stones R. C. \& Wiebers J. E. (1967) Temperature regulation in the little brown bat, Myotis lucifugus. In Mammalian Hibernation (Edited by FisheR K. C., Dawe A. R., Lyman C. P., Schonbaum E. \& South F. E., Jr.), Vol. III, pp. 97-109. Oliver \& Boyd and American Elsevier, New York.

Studier E. H. (1968) Fringe-tailed bat in northeast New Mexico. Southwest Nat. 13, 362.

Studier E. H., BeCK L. R. \& Lindeborg R. G. (1967) Tolerance and initial metabolic response to ammonia intoxication in selected bats and rodents. $\mathcal{F}$. Mammal. 48, 564-572.

Key Word Index-Chiroptera; bats; Vespertilionidae; Myotis; metabolism. 